\title{
The Effects of Obesity-Related Anthropometric Factors on Cardiovascular Risks of Homeless Adults in Taiwan
}

\author{
Ching-Lin Chen ${ }^{1,2}$, Mingchih Chen ${ }^{1,3, *}$ and Chih-Kuang Liu ${ }^{1,3,4, *}$ \\ 1 Graduate Institute of Business Administration, Fu Jen Catholic University, New Taipei City 242, Taiwan; \\ a1554@tpech.gov.tw \\ 2 Taipei City Hospital, Taipei City 10341, Taiwan \\ 3 Artificial Intelligence Development Center, Fu Jen Catholic University, New Taipei City 242, Taiwan \\ 4 Department of Urology, Fu-Jen Catholic University Hospital, New Taipei City 242, Taiwan \\ * Correspondence: 081438@mail.fju.edu.tw (M.C.); Charles.jhs@gmail.com (C.-K.L.)
}

Received: 6 August 2020; Accepted: 16 September 2020; Published: 18 September 2020

\begin{abstract}
Homelessness is a pre-existing phenomenon in society and an important public health issue that national policy strives to solve. Cardiovascular disease (CVD) is an important health problem of the homeless. This cross-sectional study explored the effects of four obesity-related anthropometric factors-body mass index (BMI), waist circumference (WC), waist-to-hip ratio (WHR), and waist-to-height ratio (WHtR) — on cardiovascular disease risks (expressed by three CVD markers: hypertension, hyperglycemia, and hyperlipidemia) among homeless adults in Taipei and compared the relevant results with ordinary adults in Taiwan. The research team sampled homeless adults over the age of 20 in Taipei City in 2018 and collected 297 participants. Through anthropometric measurements, blood pressure measurements, and blood tests, we calculated the obesity-related indicators of the participants and found those at risks of cardiovascular disease. The results showed that the prevalence of hypertension, hyperglycemia, and hyperlipidemia in homeless adults was significantly higher than that of ordinary adults in Taiwan. Among the four obesity-related indicators, WHtR showed the strongest association with the prevalence of hypertension and hyperlipidemia, followed by WHR, both of which showed stronger association than traditional WC and BMI indicators. It can be inferred that abdominal obesity characterized by WHtR is a key risk factor for hypertension and hyperlipidemia in homeless adults in Taiwan. We hope that the results will provide medical clinical references and effectively warn of cardiovascular disease risks for the homeless in Taiwan.
\end{abstract}

Keywords: homeless adults; BMI; WC; WHR; WHtR; cardiovascular risk

\section{Introduction}

Homeless individuals are defined as people without a fixed residence and fixed work [1]. The last time a global survey was attempted — by the United Nations in 2005-an estimated 100 million people were homeless worldwide [2]. Homelessness is usually caused by health problems and social factors and is related to insufficient food, alcoholism, and lack of personal hygiene [3,4]. It can also easily lead to various diseases including mental illness, respiratory disease, cardiovascular disease, and various infectious diseases, as well as the inability to pay for medical expenses [5]. These complex medical and social issues have resulted in low life expectancy and high all-cause mortality among homeless people [6-8]. Medical care of the homeless is always an important public health issue.

Cardiovascular disease (CVD) is the most important health problem for the homeless and is a major cause of death among homeless adults, at rates that exceed those in non-homeless individuals [9-11]. Slockers et al. [12] found that CVD was the most important cause of death due to disease among 
the homeless, accounting for $22 \%$ of all-cause mortality, second only to unnatural accidental death $(26 \%)$. Scott et al. [13] found that, among the homeless, the prevalence of diabetes, pre-diabetes, and metabolic syndrome (MetS) were at higher risk than in the general population. Szerlip and Szerlip [14] investigated the homeless in New Orleans and found that hypertension was present in $65 \%$ of the homeless but only in $52 \%$ of the non-homeless, and there was no difference in the prevalence of diabetes or total cholesterol. Lee et al. [15] found that, in North America, hypertension, high cholesterol, and diabetes were not more prevalent in the homeless than in the general population but were often poorly controlled. It was not easy to control hypertension, hyperlipidemia, and hyperglycemia for the homeless [16]. The prevalence of CVD risk for the homeless is often different in different regions, races, and countries.

Obesity can increase cardiovascular disease morbidity and mortality directly and indirectly. The direct effects are mediated by obesity-induced structural and functional adaptations of the cardiovascular system to accommodate excess body weight, as well as by adipokine effects on inflammation and vascular homeostasis [17]. There have been few studies on the impact of obesity factors on CVD risk of the homeless. For the general public, obesity can cause coronary heart disease, heart failure, stroke, atrial fibrillation, and sudden cardiac death and is a significant risk factor for hypertension, hyperglycemia, and hyperlipidemia [18-20]. Susceptibility to obesity-related cardiometabolic (CM) complications is not solely mediated by overall body fat mass but is largely dependent upon individual differences in regional body fat distribution and the ability of subcutaneous adipose tissue to expand [21]. Anthropometric indicators of overall obesity and abdominal obesity were often included in studies and compared to illustrate the responses to cardiovascular risks [22-24]. Amirabdollahian and Haghighatdoost [25] assessed the heart health of young people and found that waist circumference (WC) and waist-to-height ratio (WHtR) had stronger association with CM risk compared with body-weight-related measures. Nyamdorj et al. [26] studied data from 16 participating cohorts in seven countries (Chinese, Filipino, native Japanese and Japanese living in Brazil, Mongolian, native Asian Indian living in India, and migrant Asian Indian living in Mauritius) through collaborative analysis and found that WHtR had the strongest association with diabetes while body mass index (BMI) had the strongest association with hypertension in Asians.

The current study explored the effects of the obesity-related anthropometric factors on the risk of cardiovascular disease among homeless adults in Taipei City and tried to provide the government with recommendations to manage health policies for homeless adults. Statistics as of June 2018 showed that, in the past year, the public and private sectors in Taiwan provided 140,067 person-times of assistance to homeless people, including 2385 person-times of medical assistance [27]. In Taiwan, homeless adults had complex health problems, and health problems accounted for $57 \%$ of all the problems they had [28]. The government needs to provide effective healthcare services. This investigation was led by the Taipei City Hospital in Taiwan. The Taipei City Hospital and the Taipei City Social Bureau are the main institutions that take care of their health problems [29]. According to statistics from the Ministry of Health and Welfare of Taiwan, in 2018, the number of homeless people in Taiwan was 2603, of which the male-to-female ratio was $89.1 \%: 10.9 \%$. The number of homeless people in Taipei City was 669 , and the male-to-female ratio was $85.3 \%: 14.7 \%$. Taipei was the city with the largest number of homeless people in Taiwan, accounting for $25.7 \%$ of the Taiwanese homeless population [28]. Research on healthcare issues of homeless people is of great significance to inclusive social welfare.

\section{Materials and Methods}

\subsection{Study Design and Participants}

The investigation was led by the Taipei City Hospital in Taiwan. In this cross-sectional study, the sample collection was targeted at the homeless adults in the Taipei City Homeless Counseling Organizations in 2018. The study collaborated with these organizations to carry out purposive sampling. The number of participants was 297, accounting for $44.4 \%$ of the Taipei city's homeless population. 
The sample male-to-female ratio was 77.4\%:22.6\%, which was similar to Taipei's overall ratio and was sufficiently representative [28]. Our sampled population was similar to the actual street sample.

The investigation process obtained participants' anthropometric data (body height, body weight, waist circumference, hip circumference) and cardiovascular indicators (systolic blood pressure (SBP), diastolic blood pressure (DBP), fasting plasma glucose (FPG), total cholesterol (TC), triglyceride (TG), and high-density lipoprotein cholesterol (HDL-C)) through clinical examinations, and obtained participants' demographic information (gender and age). The investigation period was from 1 April 2018-30 September 2018. This study was reviewed and approved by the Research Ethics Committee of Taipei City Hospital (Case No.: TCHIRB-10805021-E).

\subsection{Testing Procedures}

The anthropometric measurements included body height, body weight, waist circumference (WC), and hip circumference (HC). Body mass index (BMI), waist-to-hip ratio (WHR), and waist-to-height ratio (WHtR) were obtained by calculation. Cardiovascular indicator measurements included blood pressure measurement and blood sampling test. Blood glucose and lipid profile were collected by blood drawing after fasting for at least eight hours. The following testing procedures were conducted in accordance with the testing standards of the Ministry of Health and Welfare [30], and the team of nurses affiliated to the hospital was responsible for completing the testing.

\subsubsection{Anthropometric Measurement}

Anthropometric measures included body height, body weight, waist circumference, and hip circumference. First, the participants removed their shoes and heavy clothes. Body height $(\mathrm{cm})$ and body weight $(\mathrm{kg})$ were recorded to the nearest $0.1 \mathrm{~cm}$ and $0.1 \mathrm{~kg}$ with an electronic height-weight scale. WC $(\mathrm{cm})$ was measured to the nearest $0.1 \mathrm{~cm}$ with a flexible steel tape measure placed midway between the lowest rib and iliac crest when participants were in a standing position at the end of an exhalation. HC $(\mathrm{cm})$ was measured to the nearest $0.1 \mathrm{~cm}$ at the widest part of the hip region in the standing position. Both circumferences were measured twice without difference over $2 \mathrm{~cm}$, and the average was calculated as the result.

\subsubsection{Blood Pressure Measurement}

During the measurement, the participant sat in a sitting position with moderate room temperature, stayed in a quiet and comfortable place, kept calm, wore loose-fitting clothes, and did not have tight sleeves. The measurement used a mercury sphygmomanometer to measure systolic $(\mathrm{mmHg})$ and diastolic blood pressure ( $\mathrm{mmHg}$ ). After measuring the blood pressure three times, the average was calculated as the result, and the interval between each measurement was 10-15 min.

\subsubsection{Blood Test}

Blood glucose and lipid profile were collected by blood drawing after fasting for at least $8 \mathrm{~h}$. During the measurement, the participant sat on a comfortable and safe blood collection chair with armrests. The nurse chose the appropriate needle and blood collection tube, wore gloves, selected the appropriate venous blood collection site, kept the needle stable during the collection, and avoided infection. Finally, fasting plasma glucose $(\mathrm{mg} / \mathrm{dL})$, total cholesterol $(\mathrm{mg} / \mathrm{dL})$, triglyceride $(\mathrm{mg} / \mathrm{dL})$, and high-density lipoprotein cholesterol $(\mathrm{mg} / \mathrm{dL})$ indicators were obtained through blood testing.

\subsubsection{Indicator Calculation and Classification}

The calculations of obesity-related indicators were as follows: $\mathrm{BMI}=$ body weight $(\mathrm{kg}) / \mathrm{height}$ squared $\left(\mathrm{m}^{2}\right), \mathrm{WHR}=\mathrm{WC}(\mathrm{cm}) / \mathrm{HC}(\mathrm{cm})$, and WHtR $=\mathrm{WC}(\mathrm{cm}) /$ height $(\mathrm{cm})$.

According to the obesity standards for Taiwan residents formulated by the Ministry of Health and Welfare [31], the BMI classification was defined as overall obesity with a BMI value greater than 
$27 \mathrm{~kg} / \mathrm{m}^{2}$; otherwise, it was non-obesity. The WC classification was defined as abdominal obesity if the WC value of men was greater than $90 \mathrm{~cm}$ or that of women was greater than $80 \mathrm{~cm}$; otherwise, it was non-obesity. We adopted the WHR cutoff of obesity recommended by the Ministry of Health and Welfare in Taiwan $[32,33]$, which was recommended as abdominal obesity if men's WHR value was greater than 0.92 or women's was greater than 0.88 ; otherwise, it was non-obesity. At present, there was no authoritative WHtR cutoff for obesity applicable to Taiwan residents. Based on the literature [33-36], we selected the WHtR obesity cutoff that was generally applicable: the WHtR classification was defined as abdominal obesity if the WHtR value was greater than 0.5 ; otherwise, it was non-obesity.

According to the diagnostic criteria of cardiovascular indicators defined by the Ministry of Health and Welfare [37], hypertension was defined as those with systolic blood pressure $\geq 140 \mathrm{mmHg}$ or diastolic blood pressure $\geq 90 \mathrm{mmHg}$ or receiving drug treatment for hypertension; hyperglycemia was defined as fasting plasma glucose $\geq 126 \mathrm{mg} / \mathrm{dL}$, or receiving drug treatment for blood glucose; hyperlipidemia was defined as total cholesterol $\geq 240 \mathrm{mg} / \mathrm{dL}$ or triglycerides $\geq 200 \mathrm{mg} / \mathrm{dL}$ or taking hypolipidemic drugs. We used the above criteria to define cardiovascular disease makers and cardiovascular disease risks.

\subsection{Statistical Analyses}

We used R software of version 3.6.3 (R core team, Vienna, Austria) to assess the prevalence of cardiovascular disease markers and the proportion of obesity among homeless adults in Taipei and identified the main anthropometric factors for cardiovascular disease risks. Descriptive statistics was used to show the magnitude and distribution of continuous variables. T-test and chi-square test were performed to analyze gender interference. The adjusted odds ratio (OR) with $95 \%$ confidence interval (CI) was calculated using logistic regression to estimate the association of obesity-related anthropometric factors with cardiovascular disease risks and assess the strengths of the association of BMI, WC, WHR, and WHtR. Statistical results were statistically significant with $p<0.05$ * (significant), $p<0.01^{* *}$ (highly significant), and $p<0.001^{* * *}$ (very highly significant).

\section{Results}

A total of 297 participants participated in the investigation. Two hundred and eighty valid data samples were obtained after processing the missing values. Through clustering, we analyzed the extreme values of the sample and found that there were a set of statistical outliers of SBP and DBP (SBP: $158 \mathrm{mmHg}$; DBP: $167 \mathrm{mmHg}$ ) and five statistical outliers of TG (TG: $994 \mathrm{mg} / \mathrm{dL}, 1074$ $\mathrm{mg} / \mathrm{dL}, 1111 \mathrm{mg} / \mathrm{dL}, 1114 \mathrm{mg} / \mathrm{dL}, 1407 \mathrm{mg} / \mathrm{dL}$ ). It had been verified that these extreme values were the true values of the actual investigation, so these values were retained. Table 1 presents the statistical description of age and measurement indicator variables.

Table 1. Statistical description of continuous variables.

\begin{tabular}{ccccccc}
\hline Variables & Minimum & First Quartile & Median & Mean & Third Quantile & Maximum \\
\hline age & 27 & 53 & 60.5 & 59.8 & 67 & 86 \\
BMI (kg/m2) & 14.2 & 20.7 & 23.8 & 24.4 & 26.8 & 46.5 \\
WC $(\mathrm{cm})$ & 63 & 81 & 89 & 89.7 & 98 & 141 \\
WHR & 0.716 & 0.882 & 0.942 & 0.935 & 0.989 & 1.146 \\
WHtR & 0.373 & 0.494 & 0.548 & 0.554 & 0.607 & 0.865 \\
SBP $(\mathrm{mmHg})$ & 93 & 120.8 & 136 & 138 & 153 & 258 \\
DBP $(\mathrm{mmHg})$ & 54 & 73 & 84 & 84.1 & 91 & 167 \\
FPG (mg/dL) & 52 & 90 & 103 & 135.5 & 137 & 542 \\
TC $(\mathrm{mg} / \mathrm{dL})$ & 92 & 146 & 170.5 & 172.5 & 193 & 342 \\
TG $(\mathrm{mg} / \mathrm{dL})$ & 31 & 97 & 143 & 196.5 & 226 & 1407 \\
HDL-C $(\mathrm{mg} / \mathrm{dL})$ & 20 & 37 & 43.5 & 46.2 & 54.3 & 99 \\
\hline
\end{tabular}

Note: BMI-body mass index; WC—waist circumference; WHR—waist-to-hip ratio; WHtR-waist-to-height ratio; $\mathrm{SBP}$ —systolic blood pressure; $\mathrm{DBP}$ —diastolic blood pressure; FPG—fasting plasma glucose; TC—total cholesterol; TG—triglyceride; HDL-C—high-density lipoprotein cholesterol.

Table 2 lists the results of $t$-test and chi-square analysis by gender. For continuous variables, there were significant differences in WHR $(p$-value $=0.0013)$, WHtR $(p$-value $=0.014)$, TC $(p$-value $=0.0014)$, 
and HDL-C ( $p$-value $<0.001$ ) between the male and female groups. For categorical variables, only the classification of abdominal obesity marked by WC had a significant difference between gender groups ( $p$-value $<0.001)$. On the whole, gender differences rarely interfered with the differences in indicators between male and female homeless adults.

Table 2. Gender-based difference analysis.

\begin{tabular}{|c|c|c|c|c|}
\hline Variables & No. $(\%)$ & Male & Female & $p$-Value \\
\hline No. $(\%)$ & 280 & $217(77 \%)$ & $63(23 \%)$ & \\
\hline age & & 59.39 & 61.03 & 0.39 \\
\hline BMI & & 24.31 & 24.61 & 0.68 \\
\hline BMI category & & & & 0.69 \\
\hline Non-obesity & $212(76 \%)$ & 166 & 46 & \\
\hline Obesity & $68(24 \%)$ & 51 & 17 & \\
\hline WC & & 90.04 & 89.29 & 0.67 \\
\hline WC category & & & & $<0.001^{* * *}$ \\
\hline Non-obesity & $129(46 \%)$ & 112 & 17 & \\
\hline Obesity & $151(54 \%)$ & 105 & 46 & \\
\hline WHR & & 0.943 & 0.909 & $0.0013^{* *}$ \\
\hline WHR category & & & & 0.07 \\
\hline Non-obesity & $86(31 \%)$ & 73 & 13 & \\
\hline Obesity & $194(69 \%)$ & 144 & 50 & \\
\hline WHtR & & 0.547 & 0.576 & 0.014 * \\
\hline WHtR category & & & & 0.09 \\
\hline Non-obesity & $74(26 \%)$ & 63 & 11 & \\
\hline Obesity & $206(74 \%)$ & 154 & 52 & \\
\hline SBP & & 137.48 & 139.65 & 0.52 \\
\hline DBP & & 84.44 & 82.98 & 0.50 \\
\hline Hypertension & & & & 0.97 \\
\hline Normal & $145(52 \%)$ & 113 & 32 & \\
\hline Abnormal & $135(48 \%)$ & 104 & 31 & \\
\hline FPG & & 138.51 & 125.08 & 0.27 \\
\hline Hyperglycemia & & & & 0.12 \\
\hline Normal & $193(69 \%)$ & 144 & 49 & \\
\hline Abnormal & $87(31 \%)$ & 73 & 14 & \\
\hline $\mathrm{TC}$ & & 168.12 & 187.59 & $0.0014^{* *}$ \\
\hline TG & & 196.59 & 196.27 & 0.99 \\
\hline Hyperlipidemia & & & & 0.09 \\
\hline Normal & $187(67 \%)$ & 151 & 36 & \\
\hline Abnormal & $93(33 \%)$ & 66 & 27 & \\
\hline HDL-C & & 44.27 & 52.73 & $<0.001^{* * *}$ \\
\hline
\end{tabular}

Note: BMI-body mass index; WC—waist circumference; WHR—waist-to-hip ratio; WHtR-waist-to-height ratio; $\mathrm{SBP}$ — systolic blood pressure; DBP—diastolic blood pressure; FPG—fasting plasma glucose; TC—total cholesterol; TG_triglyceride; HDL-C—high-density lipoprotein cholesterol. *—significant; **_highly significant; ${ }^{* * *}$ — very highly significant.

Table 3 shows the results of the logistic regression for cardiovascular disease markers for obesity-related anthropometric factors. The odds ratios (ORs) showed clear comparisons between obesity-related indicators. After adjustment for gender and age, the odds ratios and $95 \%$ confidence intervals (CIs) for hypertension for each standard deviation (SD) increase in BMI, WC, WHR, and WHtR were 1.62 (1.23-2.11), 1.85 (1.28-2.34), 1.72 (1.32-2.24), and 1.60 (1.27-2.16), respectively. By using cutoffs to classify the factors, after BMI, WC, WHR, and WHtR values changed from non-obesity to obesity, the adjusted ORs and 95\% CIs for hypertension were 2.09 (1.18-3.77), 2.00 (1.22-3.31), 2.74 (1.59-4.81) and 5.38 (2.89-10.54). Only the BMI category indicator was associated with hyperglycemia, and the adjusted OR was 2.02 (1.12-3.64). Also after adjustment for gender and age, the ORs and 95\% CIs for hyperlipidemia for each SD increase in BMI, WC, WHR, and WHtR were 1.69 (1.34-2.30), 1.64 (1.28-2.35), 1.84 (1.41-2.54), and 1.73 (1.37-2.33). By using cutoffs to classify the factors, after BMI, WC, WHR, and WHtR values changed from non-obesity to obesity, the adjusted ORs and $95 \%$ CIs for hyperlipidemia were 2.95 (1.67-5.25), 3.03 (1.77-5.31), 3.53 (1.89-6.98), and 5.18 (2.53-11.81), respectively. 
Table 3. Adjusted odds ratios (ORs) for cardiovascular disease (CVD) markers for obesity-related indicators.

\begin{tabular}{|c|c|c|c|c|c|c|c|c|c|c|c|c|}
\hline \multirow{3}{*}{$\begin{array}{l}\text { Obesity-Related } \\
\text { Factors }\end{array}$} & \multicolumn{4}{|c|}{ Hypertension } & \multicolumn{4}{|c|}{ Hyperglycemia } & \multicolumn{4}{|c|}{ Hyperlipidemia } \\
\hline & \multicolumn{2}{|c|}{ Unadjusted } & \multicolumn{2}{|c|}{ Adjusted } & \multicolumn{2}{|c|}{ Unadjusted } & \multicolumn{2}{|c|}{ Adjusted } & \multicolumn{2}{|c|}{ Unadjusted } & \multicolumn{2}{|c|}{ Adjusted } \\
\hline & $\begin{array}{c}\text { OR } \\
(95 \% \mathrm{CI})\end{array}$ & $p$ & $\begin{array}{c}\text { OR } \\
(95 \% \mathrm{CI})\end{array}$ & $p$ & $\begin{array}{c}\text { OR } \\
(95 \% \mathrm{CI})\end{array}$ & $p$ & $\begin{array}{c}\text { OR } \\
(95 \% \mathrm{CI})\end{array}$ & $p$ & $\begin{array}{c}\text { OR } \\
(95 \% \mathrm{CI})\end{array}$ & $p$ & $\begin{array}{c}\text { OR } \\
(95 \% \mathrm{CI})\end{array}$ & $p$ \\
\hline BMI & $\begin{array}{c}1.07 \\
(1.02-1.13)\end{array}$ & $0.005^{* *}$ & $\begin{array}{c}1.10 \\
(1.04-1.16)\end{array}$ & $<0.001^{* * *}$ & $\begin{array}{c}1.03 \\
(0.98-1.08)\end{array}$ & 0.29 & $\begin{array}{c}1.04 \\
(0.98-1.09)\end{array}$ & 0.17 & $\begin{array}{c}1.12 \\
(1.06-1.18)\end{array}$ & $<0.001^{* * *}$ & $\begin{array}{c}1.11 \\
(1.06-1.18)\end{array}$ & $<0.001^{* * *}$ \\
\hline WC & $\begin{array}{c}1.04 \\
(1.02-1.06)\end{array}$ & $<0.001^{* * *}$ & $\begin{array}{c}1.05 \\
(1.02-1.07)\end{array}$ & $<0.001^{* * *}$ & $\begin{array}{c}1.01 \\
(0.99-1.04)\end{array}$ & 0.16 & $\begin{array}{c}1.02 \\
(0.99-1.04)\end{array}$ & 0.14 & $\begin{array}{c}1.04 \\
(1.02-1.07)\end{array}$ & $<0.001^{* * *}$ & $\begin{array}{c}1.04 \\
(1.02-1.07)\end{array}$ & $<0.001^{* * *}$ \\
\hline WHR & $\begin{array}{c}1.07 \\
(1.03-1.11)\end{array}$ & $<0.001^{* * *}$ & $\begin{array}{c}1.08 \\
(1.04-1.12)\end{array}$ & $<0.001^{* * *}$ & $\begin{array}{c}1.04 \\
(1.00-1.08)\end{array}$ & 0.05 & $\begin{array}{c}1.03 \\
(0.99-1.07)\end{array}$ & 0.12 & $\begin{array}{c}1.07 \\
(1.03-1.12)\end{array}$ & $<0.001^{* * *}$ & $\begin{array}{c}1.09 \\
(1.05-1.14)\end{array}$ & $<0.001^{* * *}$ \\
\hline WHtR & $\begin{array}{c}1.06 \\
(1.03-1.10)\end{array}$ & $<0.001^{* * *}$ & $\begin{array}{c}1.06 \\
(1.03-1.10)\end{array}$ & $<0.001 * * *$ & $\begin{array}{c}1.02 \\
(0.99-1.05)\end{array}$ & 0.20 & $\begin{array}{c}1.02 \\
(0.99-1.06)\end{array}$ & 0.14 & $\begin{array}{c}1.08 \\
(1.04-1.11)\end{array}$ & $<0.001^{* * *}$ & $\begin{array}{c}1.07 \\
(1.04-1.11)\end{array}$ & $<0.001 * * *$ \\
\hline $\begin{array}{c}\text { BMI } \\
\text { category }\end{array}$ & $\begin{array}{c}1.76 \\
(1.02-3.08)\end{array}$ & $0.046^{*}$ & $\begin{array}{c}2.09 \\
(1.18-3.77)\end{array}$ & 0.013 * & $\begin{array}{c}1.82 \\
(1.02-3.20)\end{array}$ & 0.040 * & $\begin{array}{c}2.02 \\
(1.12-3.64)\end{array}$ & 0.018 * & $\begin{array}{c}3.06 \\
(1.74-5.41)\end{array}$ & $<0.001^{* * *}$ & $\begin{array}{c}2.95 \\
(1.67-5.25)\end{array}$ & $<0.001^{* * *}$ \\
\hline $\begin{array}{c}\text { WC } \\
\text { category }\end{array}$ & $\begin{array}{c}1.92 \\
(1.19-3.10)\end{array}$ & $0.007^{* *}$ & $\begin{array}{c}2.00 \\
(1.22-3.31)\end{array}$ & $0.006^{* *}$ & $\begin{array}{c}0.94 \\
(0.57-1.56)\end{array}$ & 0.81 & $\begin{array}{c}1.02 \\
(0.61-1.73)\end{array}$ & 0.93 & $\begin{array}{c}3.16 \\
(1.87-5.47)\end{array}$ & $<0.001^{* * *}$ & $\begin{array}{c}3.03 \\
(1.77-5.31)\end{array}$ & $<0.001^{* * *}$ \\
\hline $\begin{array}{c}\text { WHR } \\
\text { category }\end{array}$ & $\begin{array}{c}2.74 \\
(1.62-4.74)\end{array}$ & $<0.001^{* * *}$ & $\begin{array}{c}2.74 \\
(1.59-4.81)\end{array}$ & $<0.001^{* * *}$ & $\begin{array}{c}1.06 \\
(0.61-1.85)\end{array}$ & 0.84 & $\begin{array}{c}1.09 \\
(0.63-1.93)\end{array}$ & 0.75 & $\begin{array}{c}3.53 \\
(1.91-6.93)\end{array}$ & $<0.001^{* * *}$ & $\begin{array}{c}3.53 \\
(1.89-6.98)\end{array}$ & $<0.001 * * *$ \\
\hline $\begin{array}{l}\text { WHtR } \\
\text { category }\end{array}$ & $\begin{array}{c}5.49 \\
(2.99-10.63)\end{array}$ & $<0.001^{* * *}$ & $\begin{array}{c}5.38 \\
(2.89-10.54)\end{array}$ & $<0.001^{* * *}$ & $\begin{array}{c}1.43 \\
(0.80-2.64)\end{array}$ & 0.24 & $\begin{array}{c}1.46 \\
(0.81-2.73)\end{array}$ & 0.22 & $\begin{array}{c}4.97 \\
(2.46-11.20)\end{array}$ & $<0.001^{* * *}$ & $\begin{array}{c}5.18 \\
(2.53-11.81)\end{array}$ & $<0.001 * * *$ \\
\hline
\end{tabular}


Through logistic regression analysis, we found that the four obesity-related indicators were all risk factors of hypertension and hyperlipidemia. Among the category indicators that characterize obesity, WHtR had the strongest association with hypertension, followed by WHR, and the weakest was WC. For hyperlipidemia, WHtR still had the strongest association, followed by WHR, and the weakest was BMI.

\section{Discussion}

The present study explored the effects of the obesity-related anthropometric factors on the risk of cardiovascular disease among homeless adults in Taipei City. The results showed the four obesity-related indicators (BMI, WC, WHR, and WHtR) are all risk factors of hypertension and hyperlipidemia in homeless adults. The WHtR indicator showed the strongest association with the prevalence of hypertension and hyperlipidemia, followed by WHR, both of which showed stronger association than traditional BMI and WC indicators. But in particular, only the BMI category factor was associated with the prevalence of hyperglycemia in homeless adults. We found that the WHtR obesity classification with 0.5 as cutoff was very sensitive to the segmentation of patients with hypertension and hyperlipidemia, far exceeding the association between the other three obesity factors and the two CVD markers. Therefore, it can be inferred that abdominal obesity characterized by WHtR is an important risk factor for hypertension and hyperlipidemia in homeless adults in Taiwan.

According to the statistical yearbook of health promotion 2018 of the National Health Administration of the Ministry of Health and Welfare of Taiwan, among adults over 20 in Taiwan, the prevalence of hypertension was $25.7 \%$ (male: $29.3 \%$; female: $22.3 \%$ ), the prevalence of hyperglycemia was $9.3 \%$ (male: $10 \%$; female: $8.7 \%$ ), and the prevalence of hyperlipidemia was $21.6 \%$ (male: $24.5 \%$; female: $18.8 \%$ ) [38]. In our results, in homeless adults over 20, the prevalence of hypertension was $49 \%$ (male: $48 \%$; female: $49 \%$ ), the prevalence of hyperglycemia was $28 \%$ (male: $34 \%$; female: $22 \%$ ), and the prevalence of hyperlipidemia was 37\% (male: 30\%; female: 43\%). According to the 2013-2017 National Nutrition and Health Survey in Taiwan (NAHSIT) data from the National Health Administration, among adults over 20 years old in Taiwan, the prevalence of abdominal obesity (by WC) was $42.5 \%$ (male: $38 \%$; female: $46.6 \%$ ), and the prevalence of overall obesity (by BMI) was $22.3 \%$ (male: $25.3 \%$; female: $19.4 \%$ ) [39]. We found that the abdominal obesity rate (by WC) was $61 \%$ (male: $48 \%$; female: $73 \%$ ), and the overall obesity rate (by BMI) was $25 \%$ (male: $24 \%$; female: $27 \%$ ) in homeless adults. Our study and the above statistics of the general population in Taiwan both used the same cutoff standards. We have also performed gender-weighted calculations based on Table 2 to make the comparisons more reasonable. We found that the prevalence of hypertension, hyperglycemia, and hyperlipidemia, and the proportion of abdominal obesity among homeless adults in Taiwan were significantly higher than those of ordinary Taiwanese residents.

The above comparisons showed that the risk of cardiovascular disease and the prevalence of obesity of the homeless in Taiwan both were higher than those of ordinary people. But the phenomenon might be different in other parts of the world. Studies in North America found that hypertension, high cholesterol, and diabetes were not more prevalent in the homeless than in the general population [14,15]. One study in Boston found that the weight distribution of the homeless was not statistically different from that of the general population [40]; another study of homeless people in 11 US cities showed that $57 \%$ of homeless adults were overweight or obese, which was less than the $68 \%$ of obese or overweight individuals in the general US population [41]. Therefore, homeless people in different countries and regions might have different cardiovascular health and obesity characteristics. However, the reasons for the environmental and human body mechanisms behind these regionally different phenomena remain to be explored.

So, on the one hand, we speculated that abdominal obesity (especially characterized by WHtR) was the main risk factor for hypertension and hyperlipidemia among homeless adults in Taiwan; on the other hand, the risk of cardiovascular disease among homeless people in Taiwan was indeed a serious crisis, at least compared to North America. The 2019 statistics of death causes in Taiwan 
showed that, among the top 10 causes of death, the second place was heart diseases, the fourth place was cerebrovascular diseases, the fifth place was diabetes, and the eighth place was hypertensive diseases [42]. Chronic cardiovascular diseases account for four of the top 10 causes of death. Therefore, the cardiovascular health crisis of Taiwanese homeless people will only be more severe than that of the general public.

This study has several advantages. First of all, this is the first systematic study for homeless adults in Taiwan. According to the literature, no other researchers in Taiwan has conducted relevant systematic data research and analysis on homeless adults. Second, the data of this research is very representative and precious. Homeless adults are highly dissociative and move around. Collecting data related to homeless adults is very difficult, and it is more necessary to consider their personal wishes before conducting investigations. It also has some limitations. First, we used cross-sectional research design, which is unable to prove causality. Second, we conducted preliminary health examinations on the study participants, and the investigation data excluded those who were unhealthy and unable to walk. Third, we categorized CV indicators based on abnormal standards, did not ask participants if they used medication control and treatment, so the prevalence might be slightly underestimated.

Our study hope to provide education concepts and improve the obesity factors of the homeless population, thereby reducing the rate of cardiovascular disease, reducing health care expenditure, and reducing the national society cost. We recommend that Taiwanese government agencies include more comprehensive inspection items in future surveys, such as the Questionnaire on the Cognitive Test of Drug Abuse Prevention or the Brief Symptom Rating Scale, the purpose of which is to be able to quickly understand the individual's psychological care needs and then provide the required mental health services. Meanwhile, this study showed that WHtR had a stronger association with CVD risk than BMI, WC, and WHR for the homeless adults. Many studies suggested that WHtR is regarded as a better anthropometric indicator for evaluating central adiposity because of its independence of age, gender, and ethnicity [43]. We recommend that the Ministry of Health and Welfare of Taiwan refer to and draw up the WHtR cutoff standard suitable for Taiwan residents.

\section{Conclusions}

In summary, the results of this study showed that BMI, WC, WHR and WHtR were all risk factors of hypertension and hyperlipidemia in homeless adults in Taipei. The WHtR indicator showed the strongest association with the prevalence of hypertension and hyperlipidemia, followed by WHR, both of which showed stronger association than traditional BMI and WC indicators. It can be inferred that abdominal obesity characterized by WHtR is a key risk factor for hypertension and hyperlipidemia in homeless adults in Taiwan. This study is based on the actual anthropometric and blood sampling data of Taipei homeless adults. The data is representative, and the results can be extended to the Taiwan homeless adult.

Author Contributions: Conceptualization, C.-K.L. and C.-L.C.; methodology, M.C.; software, C.-L.C.; validation, M.C. and C.-L.C.; formal analysis, C.-L.C.; investigation, C.-K.L. and C.-L.C.; resources, C.-K.L.; data curation, C.-L.C.; writing—original draft preparation, C.-L.C.; writing—review and editing, M.C.; visualization, C.-L.C.; supervision, C.-K.L.; project administration, M.C.; funding acquisition, C.-K.L. All authors have read and agreed to the published version of the manuscript.

Funding: This research received no external funding.

Acknowledgments: The authors thank Ming Gu and Yi-Wei Kao from Graduate Institute of Business Administration, $\mathrm{Fu}$ Jen Catholic University, for their assistance in this manuscript. And we appreciate the data collection work by Social Work Division, Zhong-Xing Branch, Taipei City Hospital.

Conflicts of Interest: The authors declare that there are no conflicts of interest regarding the publication of this paper. 


\section{References}

1. Raoult, D.; Foucault, C.; Brouqui, P. Infections in the homeless. Lancet Infect. Dis. 2001, 1, 77-84. [CrossRef]

2. Busch-Geertsema, V.; Culhane, D.; Fitzpatrick, S. Developing a global framework for conceptualising and measuring homelessness. Habitat Int. 2016, 55, 124-132. [CrossRef]

3. Frankish, C.J.; Hwang, S.W.; Quantz, D. Homelessness and health in Canada: Research lessons and priorities. Can. J. Public Health 2005, 96, S23-S29. [CrossRef]

4. Fazel, S.; Geddes, J.R.; Kushel, M. The health of homeless people in high-income countries: Descriptive epidemiology, health consequences, and clinical and policy recommendations. Lancet 2014, 384, 1529-1540. [CrossRef]

5. Hwang, S.W.; Burns, T. Health interventions for people who are homeless. Lancet 2014, 384, $1541-1547$. [CrossRef]

6. O'Carroll, A.; Irving, N.; O'Neill, J.; Flanagan, E. A review of a GP registrar-run mobile health clinic for homeless people. Ir. J. Med Sci. 2017, 186, 541-546. [CrossRef]

7. Asibey, B.O.; Conroy, E.; Marjadi, B. Health problems and healthcare service utilisation amongst homeless adults in Africa-a scoping review. BMC Public Health 2020, 20, 1-12.

8. Roncarati, J.S.; Baggett, T.P.; O'Connell, J.J.; Hwang, S.W.; Cook, E.F.; Krieger, N.; Sorensen, G. Mortality among unsheltered homeless adults in Boston, Massachusetts, 2000-2009. JAMA Intern. Med. 2018, 178, 1242-1248. [CrossRef] [PubMed]

9. Jones, C.A.; Perera, A.; Chow, M.; Ho, I.; Nguyen, J.; Davachi, S. Cardiovascular disease risk among the poor and homeless-what we know so far. Curr. Cardiol. Rev. 2009, 5, 69-77. [CrossRef] [PubMed]

10. Kaldmäe, M.; Zilmer, M.; Viigimaa, M.; Zemtsovskaja, G.; Tomberg, K.; Kaart, T.; Annuk, M. Cardiovascular disease risk factors in homeless people. Ups. J. Med. Sci. 2011, 116, 200-207. [CrossRef]

11. Baggett, T.P.; Liauw, S.S.; Hwang, S.W. Cardiovascular disease and homelessness. J. Am. Coll. Cardiol. 2018, 71, 2585-2597. [CrossRef] [PubMed]

12. Slockers, M.; Nusselder, W.; Rietjens, J.; van Beeck, E. Homeless adults' most frequent cause of death is suicide or murder. Ned. Tijdschr. Geneeskd. 2018, 162, D2626.

13. Scott, J.; Gavin, J.; Egan, A.; Avalos, G.; Dennedy, M.; Bell, M.; Dunne, F. The prevalence of diabetes, pre-diabetes and the metabolic syndrome in an Irish regional homeless population. QJM An. Int. J. Med. 2013, 106, 547-553. [CrossRef] [PubMed]

14. Szerlip, M.I.; Szerlip, H.M. Identification of cardiovascular risk factors in homeless adults. Am. J. Med. Sci. 2002, 324, 243-246. [CrossRef]

15. Lee, T.C.; Hanlon, J.G.; Ben-David, J.; Booth, G.L.; Cantor, W.J.; Connelly, P.W.; Hwang, S.W. Risk factors for cardiovascular disease in homeless adults. Circulation 2005, 111, 2629-2635. [CrossRef]

16. Kaduszkiewicz, H.; Bochon, B. The medical treatment of homeless people. Dtsch. Aerzteblatt Int. 2017, 114, 673. [CrossRef]

17. Koliaki, C.; Liatis, S.; Kokkinos, A. Obesity and cardiovascular disease: Revisiting an old relationship. Metabolism 2019, 92, 98-107. [CrossRef]

18. Faulkner, J.L.; Bruder-Nascimento, T.; de Chantemèle, E.J.B. The regulation of aldosterone secretion by leptin: Implications in obesity-related cardiovascular disease. Curr. Opin. Nephrol. Hypertens. 2018, $27,63$. [CrossRef]

19. Xia, J.Y.; Lloyd-Jones, D.M.; Khan, S.S. Association of body mass index with mortality in cardiovascular disease: New insights into the obesity paradox from multiple perspectives. Trends Cardiovasc. Med. 2019, 29, 220-225. [CrossRef]

20. Mazidi, M.; Speakman, J.R. Impact of obesity and ozone on the association between particulate air pollution and cardiovascular disease and stroke mortality among US adults. J. Am. Heart Assoc. 2018, 7, e008006. [CrossRef]

21. Bastien, M.; Poirier, P.; Lemieux, I.; Després, J.-P. Overview of epidemiology and contribution of obesity to cardiovascular disease. Prog. Cardiovasc. Dis. 2014, 56, 369-381. [CrossRef] [PubMed]

22. Goktas, O.; Ersoy, C.; Ercan, I.; Can, F.E. General and abdominal obesity prevelances and their relations with metabolic syndrome components. Pak. J. Med. Sci. 2019, 35, 945-950. [CrossRef] [PubMed] 
23. Anchuelo, A.C.; Martínez-Larrad, M.T.; Serrano-García, I.; Perez, C.F.; Serrano-Rios, M. Body fat anthropometric indexes: Which of those identify better high cardiovascular risk subjects? A comparative study in Spanish population. PLOS ONE 2019, 14, e0216877.

24. Owolabi, E.O.; Ter Goon, D.; Adeniyi, O.V. Central obesity and normal-weight central obesity among adults attending healthcare facilities in Buffalo City Metropolitan Municipality, South Africa: A cross-sectional study. J. Health Popul. Nutr. 2017, 36, 54. [CrossRef] [PubMed]

25. Amirabdollahian, F.; Haghighatdoost, F. Anthropometric indicators of adiposity related to body weight and body shape as cardiometabolic risk predictors in british young adults: Superiority of waist-to-height ratio. J. Obes. 2018, 2018, 8370304. [CrossRef] [PubMed]

26. Decoda Study Group; Nyamdorj, R.; Qiao, Q.; Lam, T.H.; Tuomilehto, J.; Ho, S.Y.; Pitkäniemi, J.; Nakagami, T.; Mohan, V.; Janus, E.D.; et al. BMI compared with central obesity indicators in relation to diabetes and hypertension in Asians. Obesity 2008, 16, 1622-1635. [CrossRef]

27. Department of Social Wlfare, Taipei City Government. Survey on the Living Conditions of Homelessness in Taipei City in 2015. 2019. Available online: https://dosw.gov.taipei/cp.aspx?n=BA3CB911A329D65E (accessed on 15 September 2020).

28. Chen, S.-Z.; Ministry of Health and Welfare. Homelessness Handling Situation. Available online: https: //dep.mohw.gov.tw/DOS/cp-1721-9439-113.html (accessed on 15 September 2020).

29. Department of Social Wlfare, Taipei City Government. Homelessness Medical Insurance and Services; Department of Social Wlfare, Taipei City Government: Taipei, Taiwan, 2019.

30. Health Promotion Administration, Ministry of Health and Welfare. Healthy Self-Management-Correct Blood Pressure. Available online: https://health99.hpa.gov.tw/Article/ArticleDetail.aspx?TopIcNo=157\&DS=1Article (accessed on 15 September 2020).

31. Health Promotion Administration, Ministry of Health and Welfare. Self-Health Assessment Standard Weight. Available online: http://wellness.hpa.gov.tw/App_Prog/Weight_Calculate.aspx (accessed on 15 September 2020).

32. Health Promotion Administration, Ministry of Health and Welfare. Suggested Method of Waist Measurement. Available online: https://www.hpa.gov.tw/Pages/Detail.aspx?nodeid=1125\&pid=1617 (accessed on 15 September 2020).

33. Health Promotion Administration, Ministry of Health and Welfare. Evidences-Based Guideline on Adult Obesity Prevention and Management. Available online: https://www.hpa.gov.tw/Pages/EBook.aspx?nodeid= 1788 (accessed on 15 September 2020).

34. Ashwell, M.; Hsieh, S.D. Six reasons why the waist-to-height ratio is a rapid and effective global indicator for health risks of obesity and how its use could simplify the international public health message on obesity. Int. J. Food Sci. Nutr. 2005, 56, 303-307. [CrossRef]

35. Tseng, C.-H.; Chong, C.-K.; Chan, T.-T.; Bai, C.-H.; You, S.-L.; Chiou, H.-Y.; Su, T.-C.; Chen, C.-J. Optimal anthropometric factor cutoffs for hyperglycemia, hypertension and dyslipidemia for the Taiwanese population. Atherosclerosis 2010, 210, 585-589. [CrossRef]

36. Li, W.-C.; Chen, I.-C.; Chang, Y.-C.; Loke, S.-S.; Wang, S.-H.; Hsiao, K.-Y. Waist-to-height ratio, waist circumference, and body mass index as indices of cardiometabolic risk among 36,642 Taiwanese adults. Eur. J. Nutr. 2013, 52, 57-65. [CrossRef]

37. Health Promotion Administration, Ministry of Health and Welfare. Hypertension, Hyperlipidemia, Diabetes Prevention and Treatment Zone; 2020. Available online: https://www.hpa.gov.tw/Pages/List.aspx?nodeid=359 (accessed on 15 September 2020).

38. Health Promotion Administration, Ministry of Health and Welfare. Health Promotion 2018 of the National Health Administration of the Ministry of Health and Welfare of Taiwan. Available online: https://www.hpa. gov.tw/Pages/Detail.aspx?nodeid=268\&pid=12886 (accessed on 15 September 2020).

39. Chen, S.-Z.; Ministry of Health and Welfare. National Nutritional Status Change Survey Form. Available online: https://www.hpa.gov.tw/Pages/Detail.aspx?nodeid=3999\&pid=11145 (accessed on 15 September 2020).

40. Koh, K.A.; Hoy, J.S.; O'Connell, J.J.; Montgomery, P. The hunger-obesity paradox: Obesity in the homeless. J. Urban Health 2012, 89, 952-964. [CrossRef]

41. Tsai, J.; Rosenheck, R.A. Obesity among chronically homeless adults: Is it a problem? Public Health Rep. 2013, 128, 29-36. [CrossRef] [PubMed] 
42. Ministry of Health and Welfare. 2019 Statistics of Death Causes in Taiwan. Available online: https: //dep.mohw.gov.tw/DOS/np-1776-113.html (accessed on 15 September 2020).

43. Ejtahed, H.S.; Kelishadi, R.; Qorbani, M.; Motlagh, M.E.; Hasani-Ranjbar, S.; Angoorani, P.; Beshtar, S.; Ziaodini, H.; Taheri, M.; Heshmat, R. Utility of waist circumference-to-height ratio as a screening tool for generalized and central obesity among Iranian children and adolescents: The CASPIAN-V study. Pediatr. Diabetes 2019, 20, 530-537. [CrossRef] [PubMed]

C 2020 by the authors. Licensee MDPI, Basel, Switzerland. This article is an open access article distributed under the terms and conditions of the Creative Commons Attribution (CC BY) license (http://creativecommons.org/licenses/by/4.0/). 